\title{
Software for advanced ANOVA courses: A survey
}

\author{
BARBARA G. TABACHNICK and LINDA S. FIDELL \\ California State University, Northridge, California
}

\begin{abstract}
In response to a survey of faculty regarding their commercial software preferences for advanced analysis of variance courses, it was found that the most frequently used packages were SAS, SPSS ${ }^{x}$, and BMDP, all originally mainframe packages. The fourth choice, SYSTAT, was written for microcomputers but is currently also available for other host computers. Difficulty for students was the most frequently cited reason for not using one of these four packages. The most important criteria for choosing software packages were variety of designs, accuracy, and ease of use. Cost was a factor only for microcomputer licenses. Packages using the general linear model approach were paramount to some, while others would not consider such packages. Instructors decried the lack of the "ideal program," but the diversity of their desires makes it clear that no program could be ideal for all of them. Many faculty seemed unaware of newer software packages or of the extent to which older packages (particularly Minitab) have been modified; some had their choices constrained by departmental limitations. Better dissemination of information about statistical software is needed, whether it be from software publishers or through the professional literature.
\end{abstract}

Each year new statistical software packages are added to the already abundant number available, and existing packages are constantly being modified, corrected, and extended. All of the original mainframe packages are still available, and all have been (at least partially) rewritten for IBM-compatible microcomputers. New packages have been developed specifically for IBM-compatible microcomputers and some of these and others are rapidly becoming available in the Macintosh world. Most of us cannot hope to keep up with all of the latest developments in statistical software.

Although the packages offer a wide variety of statistical techniques, this paper focuses on the choice of packages for a senior-or graduate-level course in analysis of variance (ANOVA). Advanced ANOVA is the most widely taught statistical technique in graduate training programs (Aiken, West, Sechrest, \& Reno, 1990). Among the $222 \mathrm{PhD}$ programs in psychology surveyed, $65 \%$ offer a full course in ANOVA; $88 \%$ offer at least a partial course.

We were interested in learning which software packages were currently being used, which had been used in the past, and which had been evaluated and rejected, and why. We also sought to determine the importance of such dimensions as coverage of a wide variety of ANOVA designs, cost, ease of use, and whether or not the general linear model approach was available. To obtain this information, we surveyed many faculty regarding their choices among packages for this type of course.

Reprints of this article may be obtained from Barbara Tabachnick or Linda Fidell, Psychology Department, California State University, Northridge, CA 91330.

\section{METHOD}

\section{Respondents}

We attempted to reach the entire population of instructors of advanced courses in ANOVA in the United States and Canada by mailing approximately 500 packets to all psychology (but not specifically educational or clinical psychology) departments listed in the APA compendium on graduate study (American Psychological Association, 1986) that offer a master's or doctoral degree.

The packet was addressed to the department chair and contained two survey forms, each with a cover letter. The chair was asked to distribute the questionnaires to faculty who taught an advanced undergraduate or graduate course in ANOVA that might include such topics as nonorthogonal designs, Latin square, specific comparisons, and power, and used a textbook such as Keppel's (1982), Kirk's (1982), Myers's (1979), or Winer's (1971). The chair was asked to duplicate the questionnaire and cover letter as needed.

About half a dozen of the packets were undeliverable; 145 were completed and returned.

\section{Questionnaire}

The questionnaire had three sections. The first section listed eight packages in reverse alphabetic order: SYSTAT, SPSS $^{\mathbf{x}}$, SPSS PC, SOLO, SAS, MINITAB, CSS, and BMPD. (SPSS PC was distinguished from SPSS $^{x}$ because it is the only package for which the control language for the microcomputer version differs appreciably from that for the mainframe version.) Space was left for listing two additional packages. The faculty were asked to indicate whether they were currently using a package, whether they had evaluated a package but not selected it, or 
Table 1

Packages Currently or Previously Used and Packages Evaluated but Rejected $(N=139)$

\begin{tabular}{lccc}
\hline & \multicolumn{3}{c}{ Frequency of Response } \\
\cline { 2 - 4 } \multicolumn{1}{c}{ Package } & $\begin{array}{c}\text { Currently } \\
\text { Use }\end{array}$ & $\begin{array}{c}\text { Evaluated } \\
\text { But Did Not } \\
\text { Select }\end{array}$ & $\begin{array}{c}\text { Used in } \\
\text { Past But Not } \\
\text { Currently }\end{array}$ \\
\hline SPSS & 59 & 21 & 6 \\
SAS & 44 & 35 & 13 \\
BMDP & 34 & 32 & 19 \\
SYSTAT $\ddagger$ & 26 & 46 & 6 \\
SPSS PC & 17 & 37 & 4 \\
MINITAB & 16 & 34 & 12 \\
STATVIEW* & 4 & 1 & 0 \\
NCSS* $\dagger$ & 4 & 1 & 0 \\
CLR* & 4 & 0 & 1 \\
MYSTAT* $\ddagger$ & 4 & 0 & 0 \\
SOLO† & 3 & 9 & 3 \\
CSS & 0 & 9 & 0 \\
\hline
\end{tabular}

*Not included in survey list. †NCSS and SOLO are essentially the same package, the latter being distributed under license to BMD-Editor. ¥MYSTAT is an upward compatible student version of SYSTAT that is available very inexpensively and is "shrink-wrapped" with many textbooks-Editor.

whether they had used it in the past but were not currently doing so. Seven possible reasons for not using a package were supplied: (1) difficult for students, (2) statistics too limited, (3) package too unstable, (4) package not in textbook, (5) manual incomprehensible, (6) license too expensive, and (7) not widely available. The faculty were asked to give all their reasons for not selecting or currently using a package and to add additional reasons to the list if necessary.

The second section invited the faculty to rate each of seven criteria for choosing software, using a 4-point rating scale of very important, important, somewhat important, and not at all important. Criteria were cost, accuracy, variety of designs, general linear model approach, ease of use, personal familiarity, and availability to students after graduation. Two spaces were left for listing additional criteria. The third section solicited comments.

\section{RESULTS}

Among the 145 faculty who returned questionnaires, 6 indicated that the class taught was not a specialized course in advanced ANOVA, but rather a more comprehensive statistics or research methods course. The results reported come from the remaining 139 questionnaires.

\section{Software in Use}

Among the 139 respondents, $6 \%$ used no computer software packages in their advanced ANOVA courses, ${ }^{1}$ 45\% used a single package (usually either SPSS $^{x}$ or SAS), $27 \%$ used two packages, $14 \%$ used three packages, and $8 \%$ used four, five, or six.

Listed in Table 1 are, in decreasing order of current use, the software packages and the frequencies of responses to each of the three categories. The rows do not sum to 139 because many faculty had not selected, evaluated and rejected, or previously used many packages. The columns sum to more than 139 because many faculty had had experience with more than one package. Write-in packages that were mentioned by more than 3 faculty are included in Table 1.

Table 2 lists frequencies of reasons given for not using packages that had been evaluated and rejected or used in the past. One reason added by several faculty was "not accessible," indicating that the package was not available to a particular faculty member or institution (because of host limitations or cost, for example). No other additional reason was mentioned by more than 1 or 2 faculty.

\section{Criteria}

Table 3 shows ratings of the various criteria for choosing among commercial software packages. All of the listed criteria are "important," but variety of designs, accuracy, and ease of use are among the most important. There is much more variability in ratings among the other, less important criteria.

Several instructors pointed out that cost was not an important consideration for mainframe applications where

Table 2

Reasons for Not Currently Using Packages

\begin{tabular}{lcccccccc}
\hline & \multicolumn{7}{c}{ Reasons Not Using } \\
\cline { 2 - 10 } Package & $\begin{array}{c}\text { Difficult } \\
\text { for } \\
\text { Students }\end{array}$ & $\begin{array}{c}\text { Statistics } \\
\text { Too } \\
\text { Limited }\end{array}$ & $\begin{array}{c}\text { Too } \\
\text { Unstable }\end{array}$ & $\begin{array}{c}\text { Not in } \\
\text { Text }\end{array}$ & $\begin{array}{c}\text { Manual } \\
\text { Incom- } \\
\text { prehensible }\end{array}$ & $\begin{array}{c}\text { License } \\
\text { Too } \\
\text { Expensive }\end{array}$ & $\begin{array}{c}\text { Not } \\
\text { Widely } \\
\text { Available }\end{array}$ & $\begin{array}{c}\text { Not } \\
\text { Accessible }\end{array}$ \\
\hline SPSS $^{x}$ & 13 & 2 & 2 & 2 & 2 & 5 & 1 & 1 \\
SAS & 19 & 2 & 0 & 0 & 7 & 3 & 0 & 7 \\
BMDP & 19 & 3 & 0 & 1 & 2 & 8 & 5 & 5 \\
SYSTAT & 12 & 3 & 2 & 3 & 1 & 7 & 7 & 5 \\
SPSS PC & 9 & 3 & 1 & 4 & 2 & 11 & 4 & 1 \\
MINTIAB & 3 & 22 & 0 & 0 & 0 & 4 & 3 & 1 \\
STATVIEW & 0 & 1 & 0 & 0 & 0 & 0 & 0 & 0 \\
NCSS & 1 & 0 & 0 & 0 & 0 & 0 & 1 & 0 \\
SOLO & 1 & 3 & 0 & 2 & 0 & 1 & 3 & 2 \\
CSS & 0 & 0 & 0 & 1 & 0 & 0 & 6 & 2 \\
\hline
\end{tabular}


Table 3

Rated Importance of Criteria for Choosing Among Software Packages

\begin{tabular}{lcccccc}
\hline & & & \multicolumn{4}{c}{ Frequency of Rating } \\
\cline { 4 - 7 } \multicolumn{1}{c}{ Criterion } & Median & SIQR & $\begin{array}{c}\text { Very } \\
\text { Important }\end{array}$ & Important & $\begin{array}{c}\text { Somewhat } \\
\text { Important }\end{array}$ & $\begin{array}{c}\text { Not At All } \\
\text { Important }\end{array}$ \\
\hline Cost & 3.0 & 1.0 & 38 & 39 & 38 & 16 \\
Accuracy & 4.0 & 0.5 & 94 & 37 & 2 & 1 \\
Variety of designs & 4.0 & 0.5 & 102 & 27 & 3 & 4 \\
General linear model approach & 3.0 & 1.0 & 57 & 39 & 23 & 13 \\
Ease of use & 4.0 & 0.5 & 70 & 54 & 11 & 0 \\
Personal familiarity & 3.0 & 0.5 & 25 & 52 & 40 & 14 \\
Availability to students after graduation & 3.0 & 0.5 & 60 & 50 & 19 & 6 \\
\hline
\end{tabular}

the computer center or the university buys the package, but was very important if a personal computer package was licensed by a department or purchased by students. There were also strong differences of opinion not only about the importance of the general linear model approach, but also about whether or not it was a desirable feature.

Two other criteria mentioned by more than 1 or 2 instructors were the ability to handle repeated measures designs and the ability to manipulate matrices. The ability to handle repeated measures was mentioned specifically by 5 respondents, of whom 3 considered the issue to be very important, 1 important, and 1 not at all important. Of the 4 who mentioned the ability to manipulate matrices, 3 thought it was very important and 1 thought it was important.

\section{Comments}

Despite the plethora of commercial statistical software, many faculty feel that no single package is ideal for courses in advanced ANOVA. The following comment is typical of this view:

There seems to be no single package that meets all criteria for an ideal package. Biggest problem is that those [packages] that use the general linear model ... a are very powerful as long as you don't load them with too many "withinsubjects" (repeated measures) effects.

Several faculty assumed (falsely) that we were conducting the survey in anticipation of developing our own ANOVA package. They encouraged us to do so, some with specific advice; for example:

What is needed is an overall package that can handle ANOVA with many factors and at least several within subject (i.e., repeated measures) designs. It should also have multiple regression capabilities for a large number of variables, pre and post hoc tests. It should be relatively easy to use and have graphics capabilities. It should (ideally) be available on both Macintosh and IBM-PC compatible machines. I realize this is asking a lot, but I believe you could make a mint if you would offer something like this, with perhaps a scaled-down student version for about $\$ 50$.

Extensive graphics were on the wish lists of several faculty, along with menu-driven procedures and expanded data entry and data manipulation capabilities.
Faculty have strong and diverse opinions about the place of commercial software packages in teaching ANOVA. A recurrent theme was whether the major purpose of a course was (1) to teach underlying theory about ANOVA, or (2) to use software to help students understand ANOVA and to impart skills to students to be used after graduation. Many of those who eschew the use of software fall in the former camp. A typical comment was:

Do not use any canned programs in the course. Believe students should learn to do it by hand with aid of a calculator. Computer not available for exams anyway.

Or, more strongly:

I generally do not teach students how to run statistical analyses on the computer in graduate statistics courses. My position in this is that, just as we do not typically teach students how to use a word processor in courses requiring a paper, so too we should not devote class time to "technical" training in statistical analysis.

For those who use software to aid in understanding ANOVA, ease of use seems more important than availability after graduation. But there are those who emphasize training of skills for later use, as the following response indicates:

I like to use a variety of packages to point out strengths and weaknesses (and some errors). Also, this way students have a greater chance of finding something they are familiar with when they take their first job.

Some would like a package that is tied to the textbook being used (or the reverse):

Biggest need is for a package that is coordinated with commonly used psychology statistics books.

It is evident that courses using statistical software are currently in flux, with many departments deciding between mainframes and microcomputers and between IBMcompatible and Macintosh microcomputers. Some faculty seemed unaware that most mainframe packages are currently available in the microcomputer environment. Among those using Macintoshes, there is dissatisfaction with the selection of statistical packages currently available. $^{2}$ (We were chided for failing to include Macintosh packages on our survey list.) As mentioned by a typical Macintosh-using respondent: 
Course is changing. Macintosh replaced mainframe as a primary tool because of (1) graphics and (2) ease of use. Consequently have taught less ANOVA and more statistics which are available on Macs, e.g., regression.

A number of faculty were not particularly fond of the package they were using but felt constrained by the desire that a single package be used by all faculty in the department and/or for all their statistics courses. As one respondent said:

To some extent my selection of programs reflects the preferences of other faculty members who are less likely to switch even when a better program becomes available. I am having a similar problem with the acceptance of a modelcomparison/GLM approach because of the training of the older faculty.

\section{DISCUSSION}

Despite the availability of many new statistical software packages, the top three in popularity for this application, SPSS, SAS, and BMDP, appeared years ago as mainframe software. Among these, SPSS is by far the most popular, particularly when both mainframe and microcomputer versions are considered. The fourth package in terms of popularity is SYSTAT, the only one of the packages originally developed for IBM-compatible microcomputers and now also available for mainframes and Macintoshes.

Those who use no software packages tend to teach from a theoretical framework and view the packages as a technical adjunct that students can learn later, on their own, if need be. At the other extreme were faculty who teach a variety of packages plus file manipulation over networks in an effort to foster skills necessary for electronic collaboration.

Although ease of use is not the most important criterion for choosing a software package, the most frequently cited reason for not using one of the four most popular programs is difficulty for students. The fifth most popular package, MINITAB, which is considered to be userfriendly, was most often rejected because of limited statistics. Apparently many instructors were unaware (as were we) of the vastly expanded ANOVA capabilities of the latest versions of that package. It is evident, from the lack of information about MINITAB and SUPERANOVA, that instructors are not fully aware of the features of newly emerging or updated software. This may be due to inadequate advertising on the part of software firms or to failure to provide evaluation copies. While software pub- lishers might justifiably be reluctant to provide fully functional copies of their packages for evaluation, demonstration disks might be a valuable supplement to printed advertising. Or perhaps demonstration versions could be made available to institutions on a time-limited basis.

Some faculty appear to be unaware of what they already have. One member of the California State University system, for instance, seemed not to know of a system-wide license for one of the top packages.

Although a recurring complaint among faculty is that there is no ideal package, it is clear that no one package could possibly satisfy all of their differing needs. While some use only the general linear model approach, others would not consider a program that required specification of ANOVA designs in general linear model terms. Some want a program tied to a specific textbook; others want their students to be prepared for anything they might encounter in the world beyond academia.

There is currently a need for a wide variety of software packages, and there is probably a place for any that is reasonably comprehensive, fairly easy to use, accurate, and available for use without mortgaging the department. Ideally, we should all have access to recent, impartial comparisons of statistical software in our professional literature. Lacking that, it is up to software publishers to make us aware of the ANOVA package of our dreams.

\section{REFERENCES}

Aiken, L. S., West, S. G., Sechrest, L., Reno, R. R. (1990). Graduate training in statistics, methodology, and measurement in psychology: A survey of $\mathrm{Ph} . \mathrm{D}$. programs in North America. American Psychologist, 45, 721-734.

American Psychological Association (1986). Graduate study in psychology and associated fields. Washington, DC: Author.

KEPPE L, G. (1982). Design and analysis: A researcher's handbook (2nd ed.). Englewood Cliffs, NJ: Prentice-Hall.

KIRK, R. E. (1982). Experimental design: Procedures for the behavioral sciences (2nd ed.). Monterey, CA: Brooks-Cole.

MyERS, J. L. (1979). Fundamentals of experimental design (3rd ed.). Boston: Allyn \& Bacon.

WINER, B. J. (1971). Statistical principles in experimental design (2nd ed.). New York: McGraw-Hill.

\section{NOTES}

1. The percentage using no software packages may be underestimated since it seems likely that some faculty who use no packages did not return the survey.

2. Some who currently use STATVIEW, a general-purpose statistical package for the Macintosh, mentioned its limitations but seemed unaware of SUPERANOVA, a specialized analysis of variance program available from the same publisher. 